\title{
Higher Levels of Glutamate in the Associative-Striatum of Subjects with Prodromal Symptoms of Schizophrenia and Patients with First-Episode Psychosis
}

\author{
Camilo de la Fuente-Sandoval ${ }^{1,2}$, Pablo León-Ortiz², Rafael Favila ${ }^{3}$, Sylvana Stephano ${ }^{2}$, David Mamo ${ }^{4}$, \\ Jesús Ramírez-Bermúdez ${ }^{2}$ and Ariel Graff-Guerrero*,4 \\ 'Experimental Psychiatry Laboratory, Instituto Nacional de Neurología y Neurocirugía, Mexico City, Mexico; ${ }^{2}$ Neuropsychiatry Department, \\ Instituto Nacional de Neurología y Neurocirugía, Mexico City, Mexico; ${ }^{3}$ MR Advanced Applications, GE Healthcare, Mexico City, Mexico; \\ ${ }^{4}$ Multimodal Neuroimaging Schizophrenia Group, PET Centre, Centre for Addiction and Mental Health \& Department of Psychiatry, University of \\ Toronto, Toronto, ON, Canada
}

\begin{abstract}
The glutamatergic and dopaminergic systems are thought to be involved in the pathophysiology of schizophrenia. Their interaction has been widely documented and may have a role in the neurobiological basis of the disease. The aim of this study was to compare, using proton magnetic resonance spectroscopy ( ${ }^{H}$-MRS), glutamate levels in the precommissural dorsal-caudate (a dopamine-rich region) and the cerebellar cortex (negligible for dopamine) in the following: (I) 18 antipsychotic-naive subjects with prodromal symptoms and considered to be at ultra high-risk for schizophrenia (UHR), (2) 18 antipsychotic-naïve first- episode psychosis patients (FEP), and (3) 40 age- and sex- matched healthy controls. All subjects underwent a 'H-MRS study using a 3Tesla scanner. Glutamate levels were quantified and corrected for the proportion of cerebrospinal fluid and percentage of gray matter in the voxel. The UHR and FEP groups showed higher levels of glutamate than controls, without differences between UHR and FEP. In the cerebellum, no differences were seen between the three groups. The higher glutamate level in the precommissural dorsal-caudate and not in the cerebellum of UHR and FEP suggests that a high glutamate level (a) precedes the onset of schizophrenia, and (b) is present in a dopamine-rich region previously implicated in the pathophysiology of schizophrenia.
\end{abstract}

Neuropsychopharmacology (20II) 36, I78I-I79I; doi:10.1038/npp.201।.65; published online 20 April 201।

Keywords: 'H-MRS; schizophrenia; prodromal; glutamate; associative-striatum; dopamine

\section{INTRODUCTION}

Schizophrenia is a chronic mental illness characterized by psychotic or positive symptoms (hallucinations and delusions), and negative and cognitive symptoms (apathy, social withdrawal, decreased attention, decreased executive function, abnormal psychomotor speed of processing and impairment of verbal memory) (APA, 2000; Rajji et al, 2009). Despite treatment advances, schizophrenia remains as a seriously disabling, lifelong illness, that is among the world's top ten causes of long-term disability (Saraceno, 2002). The onset of schizophrenia is usually preceded by a 'prodromal phase', characterized by subthreshold psychotic symptoms, a high likelihood of a family history of

*Correspondence: Dr A Graff-Guerrero, Multimodal Neuroimaging Schizophrenia Group, PET Centre, Centre for Addiction and Mental Health, 250 College Street, Toronto, Ontario, Canada M5T IR8,

Tel: + I 416 535 8501 Ext 7376, Fax: + I 4169793855 , E-mail: ariel_graff@camh.net

Received 4 October 2010; revised 20 February 2011; accepted 23 March 2011 schizophrenia, and a decline in everyday functioning (Yung and McGorry, 1996). Longitudinal studies, in developed countries, have found that between $19 \%$ and $35 \%$ of individuals with prodromal symptoms experience conversion to a primary psychotic illness across 1- to 2.5-year follow-up intervals (Yung et al, 2003; Cannon et al, 2008; Ruhrmann et al, 2010), which provides an ideal window of opportunity to assess biomarkers associated with progression of full-blown psychotic illness.

At the present time, pharmacological management of schizophrenia is based on antagonists or partial agonists of the dopamine $\mathrm{D}_{2}$ receptors (Kapur et al, 2000; Seeman and Kapur, 2000; Mamo et al, 2007). Although pharmacotherapy improves psychotic symptoms in most patients, improvement in negative and cognitive symptoms is at best minimal (Lieberman et al, 2005), and specific therapeutic strategies have yet to be tested in adequately powered samples to fully assess their impact on the management and conversion rate of the prodromal phase (Cadenhead et al, 2010).

The clinical effect of dopamine antagonists has been the basis for 'The dopamine hypothesis of schizophrenia' 
(Howes and Kapur, 2009a), which posits an aberrant function of the dopaminergic system in patients with schizophrenia (Sato et al, 1992; Laruelle et al, 1996; AbiDargham et al, 1998; Hietala et al, 1999; Kapur, 2003). The hypothesis has been bolstered by the recent observation of an elevated striatal (18)F-dopa uptake in subjects with prodromal symptoms (Howes et al, 2009b).

Although the dopamine hypothesis has been a useful model in our understanding and study of the psychotic state, it does not explain the deteriorating course in terms of cognition and function seen in the first few years of schizophrenia. Glutamate antagonists are well known to induce positive and negative psychotic symptoms more akin to schizophrenia than the positive symptoms induced by dopamine agonists alone (Javitt, 2007). It has been proposed that this deterioration course may be partially explained by cortical neuronal toxicity secondary to enhanced glutamate exposure (Sharp et al, 2001), which in turn is thought to reflect a compensatory increase in cortical glutamatergic activity due to hypofunction of the $\mathrm{N}$-methyl-D-aspartate (NMDA) receptor (Olney and Farber, 1995).

The interaction between glutamate and dopamine is widely documented (Cepeda and Levine, 1998; Levine and Cepeda, 1998; Kulagina et al, 2001; West et al, 2003; David et al, 2005). In schizophrenia, dopaminergic dysregulation is thought to be the final common pathway resulting from an altered glutamatergic neurotransmission (Carlsson and Carlsson, 1990; Javitt and Zukin, 1991; Olney and Farber, 1995). Disruption of the cortical glutamatergic afferents induce decreased tonic dopamine release with a subsequent disinhibition of phasic dopamine release, causing abnormal responses to insignificant stimuli (Grace, 1991, 1993, 2000).

Single photon emission computed tomography (SPECT) and positron emission tomography (PET) studies in humans have provided evidence that non-competitive glutamate NMDA receptor antagonists, such as ketamine, increase amphetamine-induced dopamine release (Kegeles et al, 2000), and decrease $\mathrm{D}_{2 / 3}$ binding in the posterior cingulate cortex (Aalto et al, 2005) and striatum (Breier et al, 1998; Smith et al, 1998; Vollenweider et al, 2000). Other studies though have not supported this finding in the striatum (Aalto et al, 2002; Kegeles et al, 2002).

Recent developments in proton magnetic resonance spectroscopy $\left({ }^{1} \mathrm{H}\right.$-MRS) permit the in vivo study of the glutamatergic system (Di Costanzo et al, 2003; Abbott and Bustillo, 2006; Di Costanzo et al, 2007).

We therefore used ${ }^{1} \mathrm{H}$-MRS to compare the glutamate levels in antipsychotic-naïve subjects with prodromal symptoms, antipsychotic-naïve patients with a first episode of psychosis and sex-and-age similar healthy controls. We selected two regions of interest for our analysis: the precommissural dorsal caudate, which is characterized by a high density of dopamine receptors and dopamine afferents, and the cerebellum, a brain region with negligible quantity of dopamine receptors and absence of dopamine afferents. It was recently shown that both patients with schizophrenia and prodromal subjects have higher dopamine levels in the associative striatum (Howes et al, 2009b; Kegeles et al, 2010), of which the precommissural dorsal caudate (henceforth, dorsal caudate) is the main component (Mawlawi et al, 2001). Our hypothesis was that subjects with prodromal symptoms and patients with a first episode of psychosis would show higher glutamate than controls in the dorsal caudate as measured by ${ }^{1} \mathrm{H}$-MRS, and no differences of glutamate between groups in the cerebellum.

\section{MATERIALS AND METHODS}

\section{Clinical Sample}

The study was approved by the Ethics and Scientific Committees of the National Institute of Neurology and Neurosurgery of Mexico (INNN). All the subjects were included following successful completion of an informed consent procedure, and with written consent of both parents for subjects under 18 years old.

Eighteen subjects with ultra high-risk for schizophreniaor prodromal symptoms (UHR), and 18 patients during their first non-affective psychotic episode (FEP) were recruited from the inpatient psychiatric service, first psychotic episode clinic, and the Adolescent Program of Neuropsychiatric and Imaging Study (PIENSA) of the INNN. All subjects were interviewed using the structured clinical interview for DSM-IV (First et al, 1997) and the UHR group met Structured Interview for Prodromal Syndromes (SIPS) criteria (Miller et al, 2003) for study entry. Both groups were antipsychotic naïve, and were capable to grant informed consent. Patients were excluded if they had the following: any concomitant medical or neurological illness, current substance abuse or history of substance dependence (excluding nicotine), comorbidity of any other axis I disorders, were considered to be at high risk for suicide, or show psychomotor agitation. Use of psychotropic medications was not permitted for the duration of the study. Forty right-handed age- and gender-matched healthy controls were also recruited. The control subjects were assessed in the same manner as the patients and any subject with a history of psychiatric illness or positive familiar history for schizophrenia was excluded. All participants were screened for drugs of abuse (eg, cannabis, cocaine, heroin, opioids and benzodiazepines) before the ${ }^{1} \mathrm{H}$-MRS studies.

\section{Magnetic Resonance Studies}

The ${ }^{1} \mathrm{H}$-MRS studies were performed in a $3 \mathrm{~T}$ GE (GE Healthcare, Milwaukee, WI) whole-body scanner with a high-resolution 8-channel head coil (Invivo, Orlando, FL). The participant's head was positioned along the canthomeatal line and immobilized by means of a forehead strap. ${ }^{1} \mathrm{H}-\mathrm{MRS}$ spectra were obtained using point-resolved spectroscopy (PRESS; TE $=35 \mathrm{~ms}, \quad \mathrm{TR}=2000 \mathrm{~ms}$, spectral width $=5000 \mathrm{~Hz}, 4096$ data points used, 128 water-suppressed, and 16 water-unsuppressed averages) in volume elements (voxels) of $8 \mathrm{ml}(2 \times 2 \times 2 \mathrm{~cm})$ centered in the right dorsal caudate nucleus and right cerebellar cortex in all studied subjects. This acquisition allowed for the quantification of glutamate (Glu), $N$-acetyl-aspartate (NAA), creatine $(\mathrm{Cr})$, phosphocreatine (PCr), glycerophosphocholine (GPC), phosphocholine (PCh), and myo-inositol (mI).

The spectra were shimmed to achieve full width at half maximum (FWHM) $\leqslant 12 \mathrm{~Hz}$ (measured on the unsuppressed water signal from the voxel), and spectra with larger 
FWHM were excluded. The voxels were defined in a $\mathrm{T}_{1}$ weighed volumetric image in axial projection (SPGR, $\mathrm{TE}=5.7 \mathrm{~ms}, \mathrm{TR}=13.4 \mathrm{~ms}, \mathrm{TI}=450 \mathrm{~ms}$, flip angle $=20^{\circ}$, $\mathrm{FOV}=25.6 \mathrm{~cm}, 256 \times 256$ matrix, slice thickness $=1.2 \mathrm{~mm}$ ) and oriented above and parallel to the anterior (AC) to the posterior commissure (PC).

The lower end of the dorsal caudate (or associativestriatum) voxel was located $3 \mathrm{~mm}$ dorsal to the $\mathrm{AC}$, including the maximum amount of gray matter and with a dorsal extension (thickness) of $2 \mathrm{~cm}$. The cerebellar voxel was located in the cerebellar cortex below the inferior cerebellar peduncle avoiding the midline (Figure 1). All spectra were analyzed with the Linear Combination Model included in the LCModel program, version 6.2-1T (Provencher, 1993). The metabolites included in the basis set were as follows: L-alanine (Ala), aspartate (Asp), $\mathrm{Cr}$, $\gamma$-aminobutyric acid (GABA), glucose (Glc), glutamine (Gln), Glu, GPC, PCh, L-lactate (Lac), mI, NAA, $\mathrm{N}$ - acetylaspartylglutamate acid (NAAG), Scyllo-inositol (Scyllo), taurine (Tau), $\mathrm{Cr}$ methylene group (-CrCH2), guanidinoacetate (Gua), GPC + PCh, NAA + NAAG, Glu + Gln, lipids (Lip), and macromolecules (MM): Lip13a, Lip13b, Lip09, MM09, Lip20, MM20, MM12, MM14, MM17, Lip13a + Lip13b, MM14 + Lip13a + Lip13b + MM12, MM09 + Lip09, and MM20 + Lip20. All metabolites with Cramer-Rao lower-bound $>20 \%$ reported by LCModel were excluded.

SPGR scans used for localization of the voxels were subsequently segmented into gray matter, white matter, and cerebrospinal fluid (CSF) using Statistical Parametric Mapping 8 (Friston et al, 1995) (SPM8, Wellcome Department of Cognitive Neurology, London; http://www.fil.ion. ucl.ac.uk/spm). Then, the size and location of each area from the spectra file headers were extracted to calculate the percentage of gray, white, and CSF content within the voxel, allowing for correction of the CSF fraction of the spectroscopic values. CSF correction assumed zero metabolite concentration in the CSF using the equation $S V_{\text {corr }}=S V /$ $(1-C S F)$, where $S V$ are the spectroscopic values, CSF is the CSF fraction within the voxel and $S V_{\text {corr }}$ are the corrected spectroscopic values.

\section{Statistical Analysis}

The results are presented in means and standard deviations $( \pm S D)$. Statistical analyses were performed using SPSS v16.0 software (SPSS, Chicago, IL). Demographic and clinical characteristics of the sample were compared between controls, FEP, and UHR groups with analysis of variance (ANOVA), with the exception of frequency data. Frequency data were analyzed using $\chi^{2}$ or Fisher's exact tests. Metabolite measures between groups were compared using a general linear model (GLM). The percentages of gray matter in the dorsal caudate and cerebellum, as well as age were included as covariates in the GLM. On the basis of significant main effects per metabolite and region, post hoc comparisons with Bonferroni correction were performed. The statistical comparisons were carried out at a significance level set at $p<0.05$.

Partial Spearman correlations controlling for the effect of gray matter were conducted to examine the relationship between clinical scales and Glu concentration for each region. Spearman correlations (non-parametric) rather than Pearson coefficients were used due to the relatively small sample size. The statistical threshold was established with $p \leqslant 0.05$ to control for multiple comparisons, $p=0.05 / 4$ clinical scales for UHR group (SIPS positive, negative, disorganization, general), and $p=0.05 / 3$ clinical scales for FEP (PANSS positive, negative, and general).

\section{RESULTS}

\section{Demographic and Clinical Characteristics}

The UHR group was younger than the FEP $\left(\mathrm{F}_{[2,73]}=3.60\right.$, $p=0.03$ ), but both groups did not differ from controls. Education was higher in controls compared with FEP and UHR groups $\left(\mathrm{F}_{[2,73]}=9.59, p<0.001\right)$. One subject in the UHR and two in the FEP groups previously used cannabis (Fisher's exact test $=6.12, p=0.03$ ). Four subjects in the UHR group were taking a selective serotonin reuptake inhibitor (two fluoxetine, one paroxetine, one sertraline) at the time of the study (Fisher's exact test $=9.26, p=0.005$ ). UHR and FEP groups did not differ in gender, handedness, or tobacco use compared with controls (see Table 1).

\section{Cerebral Metabolites}

There was a significant difference in Glu levels in the dorsal caudate between groups $\left(\mathrm{F}_{[2,73]}=5.99, p=0.004\right)$. Post hoc tests revealed higher Glu in both UHR and FEP groups than controls $(p=0.04$ and $p=0.01$, respectively), with no statistical difference between FEP and UHR groups $(p=0.64)$. On the contrary, cerebellar Glu concentrations did not differ significantly between the three groups
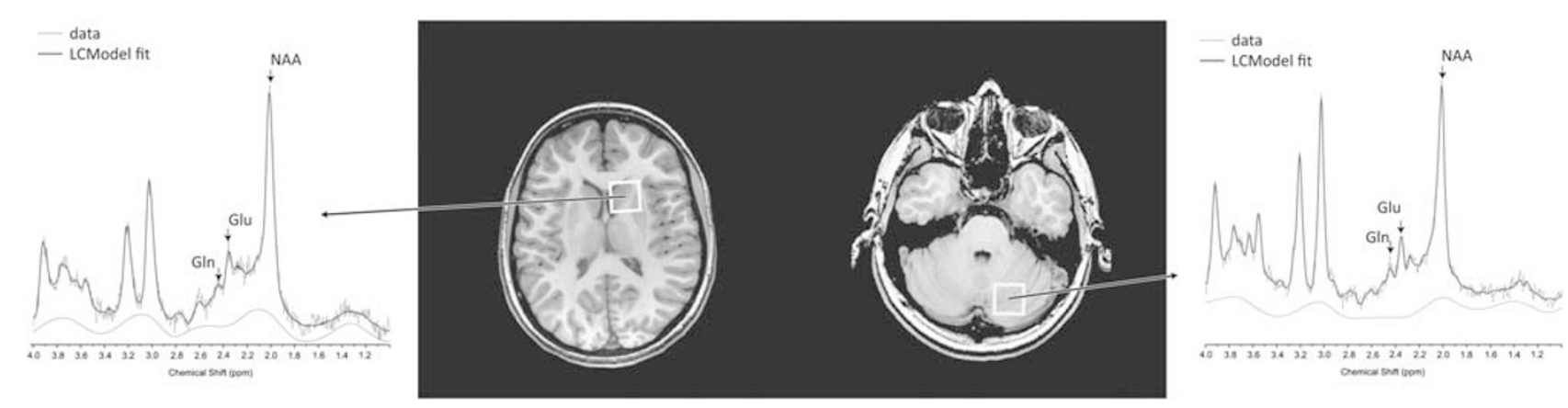

Figure I Spectroscopic voxel placement in right dorsal caudate and right cerebellum and representative spectra for each region. Glu, glutamate; Gln, glutamine; NAA, N-acetylaspartate. 
Table I Demographic and Clinical Characteristics of the Sample

\begin{tabular}{|c|c|c|c|c|}
\hline & Control subjects & UHR & FEP & Statistic \\
\hline Age $( \pm S D)$ years & $21.83 \pm 4.47$ & $19.56 \pm 3.46$ & $23.44 \pm 4.93^{\mathrm{a}}$ & $F_{[2,73]}=3.60, p=0.03$ \\
\hline Gender (male/female) & $28 / 12$ & $14 / 4$ & $10 / 8$ & Fisher's = 2.09 NS \\
\hline Education $( \pm S D)$ years & $14.47 \pm 3.32$ & $10.67 \pm\left. 2.6\right|^{b}$ & $|2.11 \pm 3.5|^{b}$ & $F_{[2,73]}=9.60, p<0.001$ \\
\hline Handedness (right/left) & $40 / 0$ & $18 / 0$ & $18 / 0$ & NS \\
\hline Length of illness $( \pm S D)$ weeks & NA & $16.56 \pm 12.28$ & $18.72 \pm 18.14$ & NS \\
\hline Cannabis (ever used) & $0 / 40$ & $1 / 18$ & $2 / 18$ & Fisher's $=6.12, p=0.03$ \\
\hline Use of antipsychotic treatment & $0 / 40$ & $0 / 18$ & $0 / 18$ & NS \\
\hline Use of SSRIs & $0 / 40$ & $4 / 18$ & $0 / 18$ & Fisher's $=9.26, p=0.005$ \\
\hline PANSS positive symptoms & & & $22.17 \pm 3.94$ & \\
\hline PANSS negative symptoms & & & $26.72 \pm 6.87$ & \\
\hline SIPS general symptoms & & $8.94 \pm 3.55$ & & \\
\hline
\end{tabular}

Abbreviations: NA, not applicable; NS, not significant; SSRIs, selective serotonin reuptake inhibitors.

Significant post hoc pair-wise comparisons with Bonferroni correction $(p<0.05)$ are indicated: ${ }^{a} v s$ UHR; ${ }^{b}$ vs controls

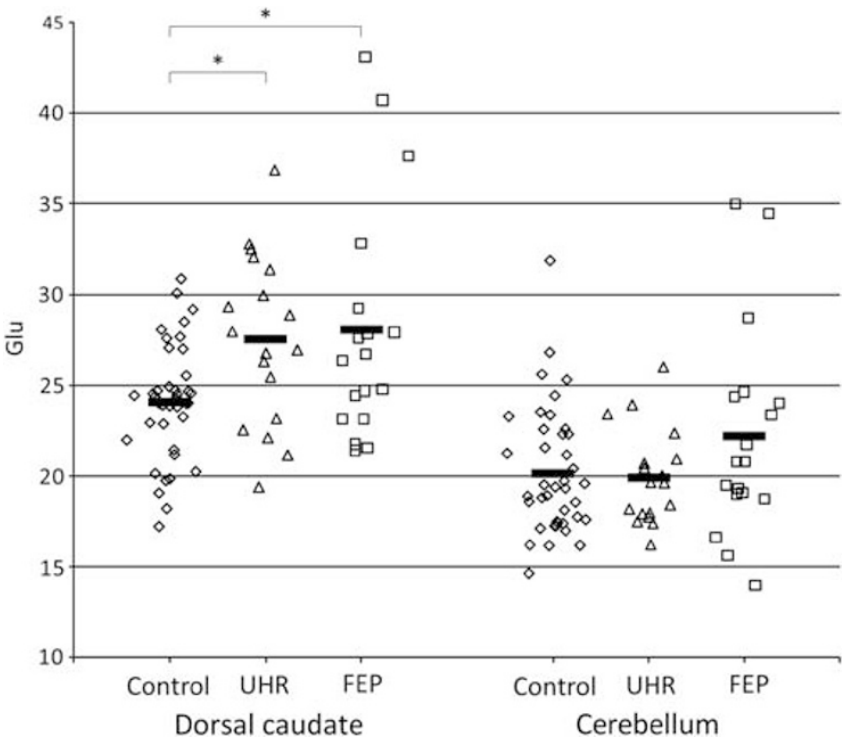

Figure 2 Glutamate (Glu) levels of each participant in the dorsal caudate and cerebellum of controls, ultra high-risk for schizophrenia (UHR), and first episode-psychosis patients (FEP). Bars represent the mean for that group. *vs control, $p<0.05$.

$\left(\mathrm{F}_{[2,73]}=1.41, p=0.25\right)$ (Figure 2). Glutamine (Gln) was not analyzed due to poor spectra fitting in the caudate (number of spectra rejected in controls $=37, \quad U H R=18$, and $\mathrm{FEP}=17$ ) and the cerebellum (number of spectra rejected in controls $=40, \mathrm{UHR}=18$, and $\mathrm{FEP}=18$ ).

NAA levels in the dorsal caudate were higher among patient groups $\left(\mathrm{F}_{[2,73]}=6.72, p=0.002\right)$, with higher NAA in the UHR group compared with controls $(p=0.002)$. Although NAA was also higher in the FEP group, this finding did not survive correction for multiple comparisons
(Table 2). We also found a difference in NAA concentration between groups in the cerebellum $\left(\mathrm{F}_{[2,73]}=7.65, p=0.001\right)$, with higher NAA in the FEP group $v s$ both controls $(p=0.003)$ and the UHR group $(p=0.001)$.

GPC + PCh concentrations, for which we had no a priori hypotheses, in the dorsal caudate and cerebellum were different between groups $\left(\mathrm{F}_{[2,73]}=7.57, \quad p=0.001\right.$ and $\mathrm{F}_{[2,73]}=4.03, p=0.02$, respectively), with higher $\mathrm{GPC}+$ $\mathrm{PCh}$ in the FEP group compared with controls in the dorsal caudate $(p=0.002)$, as well as the cerebellum $(p=0.03)$.

No differences in Glu + Gln were found between groups in dorsal caudate $\left(\mathrm{F}_{[2,73]}=2.11, p=0.13\right)$. Although an effect was found in Glu + Gln in the cerebellum $\left(\mathrm{F}_{[2,73]}=3.39\right.$, $p=0.04)$, post hoc analysis did not show any differences between groups.

The results of metabolite comparisons did not change when age was included as a covariate (data not shown). No significant correlations were found in the dorsal caudate or cerebellum between any clinical measure in UHR or FEP groups and all the metabolites concentrations.

The percentages of gray matter in the dorsal caudate and cerebellum were different between the three groups $\left(\mathrm{F}_{[2,73]}=3.44, \quad p=0.04, \quad \mathrm{~F}_{[2,73]}=9.38, \quad p=0.001\right.$, respectively). The post hoc analysis showed that the gray matter in the dorsal caudate was lower in the UHR group than in FEP $(p=0.03)$. The gray matter in the cerebellum was lower in the FEP in comparison with controls $(p=0.002)$ and with UHR $(p=0.001)$. Besides the differences of the percentage of gray matter found in dorsal caudate and cerebellum between the groups, the results of metabolites comparisons did not change whether or not the percentages of gray matter were included as a covariate (data not shown).

Glu and NAA levels were correlated in the caudate and cerebellum of all participants $(r=0.77, p \leqslant 0.001$ and $r=0.71, p \leqslant 0.001$, respectively). Moreover, Glu and NAA 
Table 2 Means $( \pm S D)$ for Each Metabolite in Dorsal Caudate and Cerebellum

\begin{tabular}{|c|c|c|c|c|c|c|c|c|c|}
\hline & \multirow{2}{*}{$\begin{array}{l}\text { Region } \\
\text { Group }\end{array}$} & \multicolumn{3}{|c|}{ Dorsal caudate } & \multirow{2}{*}{ Statistic } & \multicolumn{3}{|c|}{ Cerebellum } & \multirow{2}{*}{ Statistic } \\
\hline & & Control & UHR & FEP & & Control & UHR & FEP & \\
\hline \multirow[t]{2}{*}{ Glu } & & $24.08 \pm 3.16$ & $27.54 \pm 4.67^{\mathrm{a}}$ & $27.79 \pm 4.29^{a}$ & $F_{[2,73]}=5.99$ & $20.25 \pm 3.01$ & $19.78 \pm 2.13$ & $22.94 \pm 4.57$ & $F_{[2,73]}=1.41$ \\
\hline & & $n=40$ & $n=18$ & $n=18$ & $p=0.004$ & $n=40$ & $n=18$ & $n=18$ & $p=0.25$ \\
\hline \multirow[t]{2}{*}{ NAA } & & $21.45 \pm 2.30$ & $24.69 \pm 2.52^{\mathrm{a}}$ & $23.09 \pm 3.02$ & $F_{[2,73]}=6.72$ & $15.45 \pm 2.75$ & $14.56 \pm 2.07$ & $19.03 \pm 3.94^{\mathrm{a}, \mathrm{b}}$ & $F_{[2,73]}=7.65$ \\
\hline & & $n=40$ & $n=18$ & $n=18$ & $p=0.002$ & $n=40$ & $n=18$ & $n=18$ & $p=0.001$ \\
\hline \multirow[t]{2}{*}{$\mathrm{GPC}+\mathrm{PCh}$} & & $4.24 \pm 3.22$ & $4.65 \pm 0.28$ & $4.89 \pm 0.70^{\mathrm{a}}$ & $F_{[2,73]}=7.57$ & $4.63 \pm 0.83$ & $4.57 \pm 0.42$ & $5.43 \pm 1.13^{\mathrm{a}}$ & $F_{[2,73]}=4.03$ \\
\hline & & $n=40$ & $n=18$ & $n=18$ & $p=0.001$ & $n=40$ & $n=18$ & $n=18$ & $p=0.02$ \\
\hline $\mathrm{ml}$ & & $9.01 \pm 1.87$ & $8.87 \pm 1.72$ & $10.14 \pm 1.21$ & $F_{[2,73]}=3.11$ & $14.68 \pm 2.43$ & $|2.8| \pm 1.7 \mid$ & $14.46 \pm 2.66$ & $F_{[2,73]}=3.01$ \\
\hline
\end{tabular}

Abbreviations: Cr, creatine; FEP, first episode of psychosis group; Gln, glutamine; Glu, glutamate; GPC, glycerophosphocholine; ml, myo-inositol; n, number of spectra analyzed; NAA, N-acetyl-aspartate; PCh, phosphocholine; PCr, phosphocreatine; UHR, ultra high-risk for schizophrenia group.

Significant post hoc pair-wise comparisons with Bonferroni correction $(p<0.05)$ are indicated: ${ }^{a} v s$ controls; ${ }^{b} v s$ UHR.
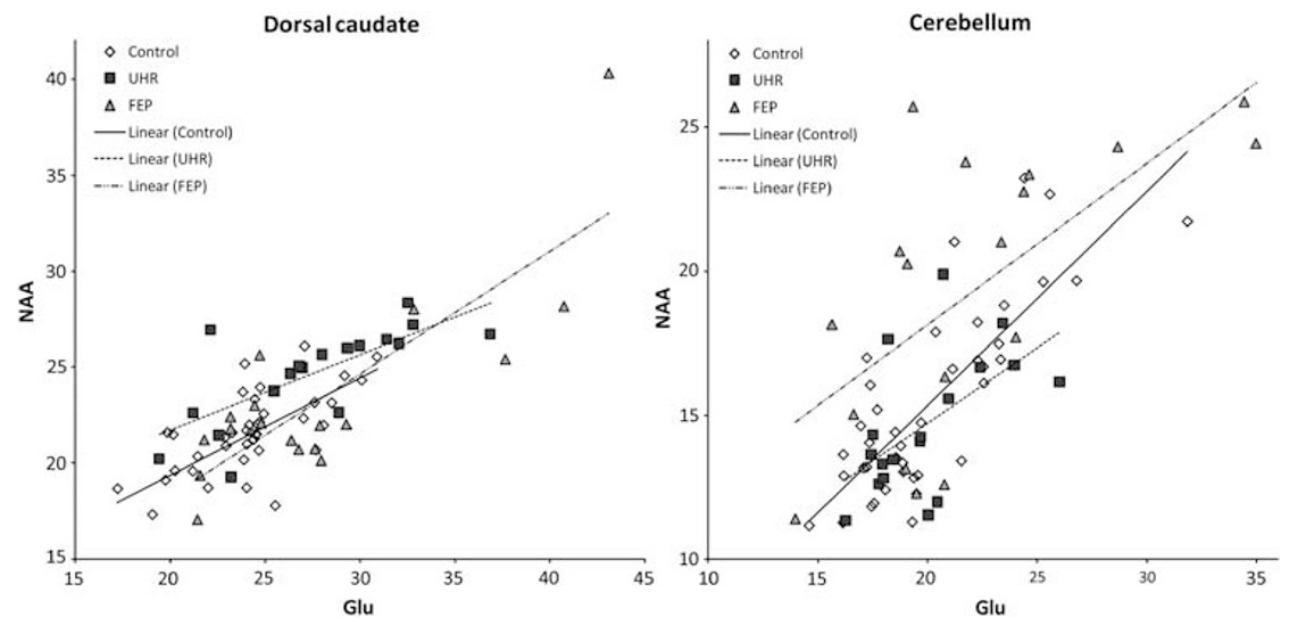

Figure 3 Correlation between glutamate (Glu) and N-acetylaspartate (NAA) in the dorsal caudate and cerebellum of the participants. Dorsal caudate: Pearson's $r=0.70, p \leqslant 0.00 \mathrm{I}$ in controls, Pearson's $r=0.74, p \leqslant 0.00 \mathrm{I}$ in ultra high-risk for schizophrenia (UHR), Pearson's $r=0.78, p \leqslant 0.00 \mathrm{I}$ in first episodepsychosis patients (FEP). Cerebellum: Pearson's $r=0.8 \mathrm{I}, p \leqslant 0.00 \mathrm{I}$ in controls, Pearson's $r=0.56, p=0.0 \mathrm{I}$ in UHR, Pearson's $r=0.64, p=0.002$ in FEP.

levels were correlated in the caudate of controls $(r=0.70$, $p \leqslant 0.001)$, UHR $(r=0.74, p \leqslant 0.001)$, and FEP groups $(r=0.78, \quad p \leqslant 0.001)$, and the cerebellum of controls $(r=0.81, p \leqslant 0.001)$, UHR $(r=0.56, p=0.01)$, and FEP groups $(r=0.64, p=0.002)$ (Figure 3 ).

\section{DISCUSSION}

\section{Summary of Main Results}

Our results confirmed our hypothesis that subjects with prodromal symptoms of schizophrenia and unmedicated subjects experiencing a first episode of psychosis, have increased Glu in the dorsal caudate but not in the cerebellum. The absence of differences in the cerebellum suggests that the alterations in Glu in subjects with psychotic and pre-psychotic symptoms are not ubiquitous within the brain, and that the differences may be restricted to brain dopamine-rich regions such as the associative striatum, a region thought to be involved in the pathophysiology of schizophrenia (Howes et al, 2009b; Kegeles et al, 2010).

The associative striatum (or cognitive striatum) (Mawlawi et al, 2001) includes the rostral and dorsal part of the caudate nuclei or precommissural dorsal section, also known as neostriatum (Brodal, 2004). This structure is rich in dopamine afferents and $\mathrm{D}_{2}$ receptors, and is frequently included in the quantification of in vivo occupancy of 
antipsychotics (Farde et al, 1988; Graff-Guerrero et al, 2008). In addition, the associative striatum establishes major connections with the frontal lobe (Lehericy et al, 2004). The frontal cortex has been implicated in the neurocognitive deficits seen in schizophrenia (Villalta-Gil et al, 2006), deficits which are also present in subjects with prodromal symptoms and FEP patients (Cadenhead, 2002; Jahshan et al, 2010).

The associative striatum, and especially the precommissural dorsal caudate, has shown the highest $\mathrm{D}_{2}$ receptor availability after acute pharmacologically induced dopamine depletion in antipsychotic-free patients with schizophrenia (Kegeles et al, 2010). In this same study, no differences in receptor availability were seen in the other functional subdivisions of the striatum (limbic and sensorimotor striatum), suggesting that schizophrenia is associated with elevated dopamine function in associative regions of the striatum. Moreover, UHR subjects had elevated DOPA decarboxylase activity in this same functional region, suggesting that the subcortical dopamine synthesis is enhanced before the expression of psychosis (Howes et al, 2009b).

Although our main interest was to explore the differences in Glu associated with a dopamine rich region, we included the cerebellar cortex for comparison. The cerebellar cortex has a negligible amount of dopamine receptors and has no dopamine afferents (De Keyser et al, 1988; Camps et al, 1989). On the other hand, both the dorsal caudate and the cerebellar cortex are abundant in glutamatergic cells (Brodal, 2004) and cortical afferents from the frontal cortex (Schmahmann and Pandya, 1995; Middleton and Strick, 2001; Dum and Strick, 2003; Kelly and Strick, 2003). In this sense, one of the differences between the dorsal caudate and the cerebellum are the dopaminergic afferents, which are restricted to the dorsal caudate. Although it is tempting to speculate that some differences observed in the Glu in the dorsal caudate may be related to the dopaminergic tone, our study was not designed to address this question. Although, in agreement with our results, preclinical studies have shown that elevation in striatal endogenous Glu induces an increase in striatal dopamine release (Segovia et al, 1997). Preliminary results from our group (de la Fuente-Sandoval et al, 2009) have shown that patients with schizophrenia during an acute psychotic episode and after 6 weeks of antipsychotic treatment presented with higher Glu levels in the dorsal caudate compared with controls, and with no differences in the cerebellum. These data suggest that higher Glu levels are a stable finding in the dorsal caudate regardless of treatment. However, we acknowledge that to confirm the association between higher Glu with dopamine, a direct measure of both Glu and dopamine should be performed in the same subject.

\section{Glutamate-Dopamine Interaction and Schizophrenia}

Abnormal interaction between Glu and dopamine neurotransmission systems has been shown in preclinical model of schizophrenia (Grace, 2000). In addition, using SPECT in normal controls, Kegeles et al. (Kegeles et al, 2000) demonstrated that ketamine administration enhanced an increase in amphetamine-induced dopamine release. In a
PET study, ketamine administration resulted in a decrease in striatal $\left[{ }^{11} \mathrm{C}\right]$-raclopride binding, reflecting an increase on striatal synaptic dopamine. Moreover, this decrease in $\left[{ }^{11} \mathrm{C}\right]$-raclopride binding was similar to the decrease shown after amphetamine administration (Breier et al, 1998). Others (Smith et al, 1998; Vollenweider et al, 2000; Aalto et al, 2005) have also documented this interaction, concluding that glutamatergic antagonism is associated to an increase of dopamine release in the cerebral cortex and the striatum, and inducing positive and negative symptoms similar to those observed in schizophrenia. In addition, NMDA-receptor blockade in healthy humans has been shown to increase Gln levels in the anterior cingulate as measured by ${ }^{1} \mathrm{H}-\mathrm{MRS}$ (Rowland et al, 2005).

Glu system dysfunction has been suggested to have a role in schizophrenia (Carlsson and Carlsson, 1990; Javitt and Zukin, 1991; Olney and Farber, 1995). Uncompetitive NMDA receptor antagonists, such as phencyclidine (PCP) and ketamine, induce the full range of positive and negative psychotic symptoms observed in schizophrenia patients (Javitt, 2007). In rats, ketamine administration produced an increase in glutamate release in prefrontal cortex (Moghaddam et al, 1997).

The results of this study, which show higher Glu levels in subjects with pre-psychotic and psychotic symptoms in the dorsal caudate, a brain region previously associated with enhanced dopaminergic transmission in schizophrenia, are consistent with our hypothesis. However, it is important to note that direct measurement of Glu neurotransmission is not possible with ${ }^{1} \mathrm{H}$-MRS. This technique measures both metabolic and vesicular Glu. A summary of findings from previous studies that measured Glu are presented in Table 3. The reasons for the discrepant findings between studies are unclear; nevertheless, our study illustrates, using a within subject design, that Glu levels are elevated in the dorsal caudate in comparison with the cerebellum.

\section{Glutamate and Neuronal Degeneration}

Excessive glutamatergic activity is also associated with neuronal degeneration (Olney et al, 1989). Our study revealed a lower percentage of gray matter in caudate voxels of UHR participants, which may be secondary to excessive glutamate levels. Other studies have also reported a decrease in gray matter in UHR subjects in a variety of other brain regions, including the right medial temporal, lateral temporal, orbitofrontal and cingulate cortex, insula, and inferior frontal and superior temporal gyrus (Pantelis et al, 2003; Borgwardt et al, 2007; Stone et al, 2009). Other factors, however, may have also contributed to our finding of reduced gray matter as a lower percentage of gray matter was not observed in FEP patients. Moreover, our study was not intended to compare gray matter differences between regions, which were principally included in this study as a covariate. As noted above, no differences were seen in the metabolites results whether or not we included this measure as a covariate. Interestingly, we found a decrease in cerebellar gray matter of the FEP group compared with UHR subjects and controls. This finding agrees with previous studies of FEP, drug-naïve patients (Jayakumar et al, 2005; Chua et al, 2007). 
Table 3 Summary of Glutamate 'H-MRS Studies

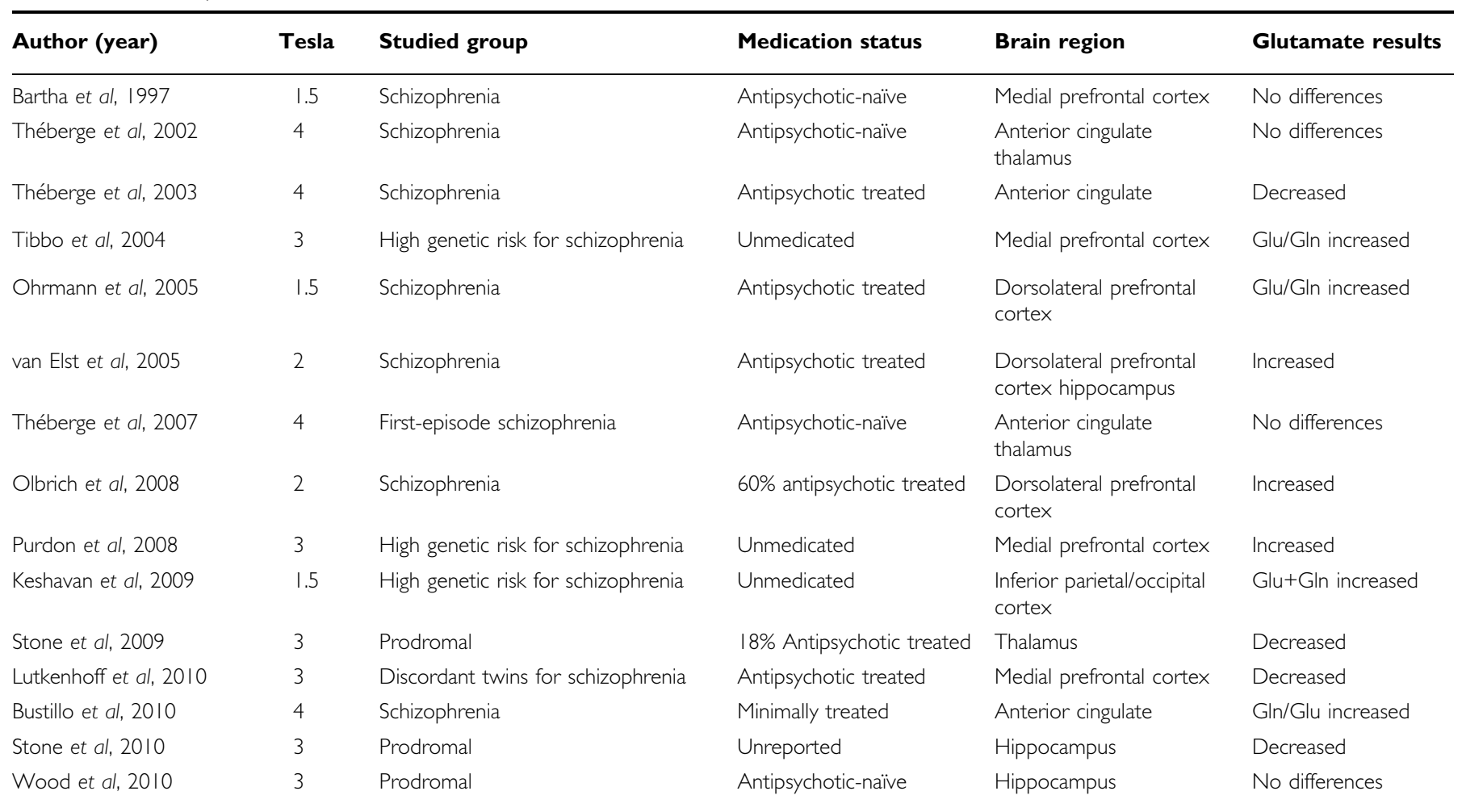

Abbreviations: Gln, glutamine; Glu, glutamate.

\section{Other Metabolites}

Our results indicate that Glu levels are significantly correlated with NAA in the caudate and cerebellum in all comparison groups. NAA, one of the prominent peaks consistently shown in ${ }^{1} \mathrm{H}$-MRS, is present almost exclusively in neurons and is thought to be a marker of neuronal functional integrity (Barker, 2001) and axonal mitochondrial metabolism (Bates et al, 1996). Higher NAA levels may be driven by increased axonal mitochondrial metabolism to maintain axonal conduction (Ariyannur et al, 2008). It is not surprising then that an increase in Glu, an excitatory neurotransmitter, would be associated with an increase in local neuronal metabolism.

We report higher NAA in the cerebellum of FEP patients compared with both controls and UHR subjects. This is inconsistent with the findings of a recent meta-analysis, (Steen et al, 2005) which found no difference in NAA levels between patients with schizophrenia and controls. Another study of early schizophrenia patients with minimal antipsychotic exposure also found no differences in the cerebellum compared with controls (Bustillo et al, 2008). The reasons for these discrepant findings are unclear, but may be related to the clinical status of patients, previous exposure to antipsychotic medication, spectroscopic acquisition (single-voxel $v s$ chemical shift imaging and varying echo time), and the use of ratios (NAA to Cre or Cho) vs metabolite concentrations. Future replication studies are necessary to shed light on these discrepant findings.

Elevated choline containing compounds levels (represented collectively as GPC + PCh) have been interpreted as supportive of the 'membrane hypothesis' of schizophrenia (Horrobin et al, 1994), suggesting that phospholipid disturbances and an increased myelin degradation supports a generalized membrane disorder in patients with schizophrenia (Auer et al, 2001). Our results in elevated choline containing compounds (GPC $+\mathrm{PCh}$ ) found in the dorsal caudate of FEP patients agrees with previous reports in patients with schizophrenia (Bustillo et al, 2002; Lutkenhoff et al, 2010), and in childhood-onset schizophrenia (O'Neill et al, 2004). Three previous reports have failed to find differences in choline in the cerebellum of patients with schizophrenia (Eluri et al, 1998; Tibbo et al, 2000; Bustillo et al, 2008).

Glycerophosphocholine is one the main products of membrane phospholipid breakdown. The observed increase in the FEP group but not in the UHR suggests increased membrane turnover that occurs after a switch to FEP, and may result from changes in membrane mass or proliferation of dendrites and synaptic connections in these regions (Stanley et al, 2006).

\section{Limitations}

Limitations of this study need to be considered. First, we did not include cognitive evaluations: we therefore could not address the possibility of an effect of cognition associated with Glu levels. Second, the groups could not be matched for education; education was greater in controls than in FEP and UHR. Parental education and socioeconomic status were not collected but would be better variables for subject matching given that the subjects 
groups were young and became ill before reaching full educational potential. Third, the spectroscopic voxels involved functionally dissimilar areas and included different proportions of CSF, gray and white matter, making interpretations regarding tissue specificity problematic. We tried to minimize this limitation by correcting for CSF proportion and using the gray matter as a covariate. Although we found differences in dorsal caudate and cerebellum gray matter percentage between the groups, this did not change the results. Fourth, altered NAAG has been described in schizophrenia. Although NAAG could contribute to the quantification of NAA, it could not be differentiated in a reliable way with the methodology employed in our study (Lutkenhoff et al, 2010). Specific techniques to measure NAAG (Edden et al, 2007) could be used in future studies. Fifth, Glu-Gln contamination of the NAA peak has been observed at short echo times, including the one used in this study ( $\mathrm{TE}=35 \mathrm{~ms}$ ) (Clementi et al, 2005). Thus, this could be reflected as an artificial increase of NAA when Glu is increased. However, this is unlikely as at least the dorsal caudate of FEP showed higher Glu with no difference in NAA levels. Further studies using specific techniques to measure Glu, such as multiple echo times (Zhang et al, 2007), TE-averaged PRESS (Hurd et al, 2004), or constant time PRESS (Mayer and Spielman, 2005) are needed.

\section{Summary}

Our results indicate an increase in Glu in the dorsal caudate of antipsychotic naïve subjects with prodromal symptoms of schizophrenia and at a FEP, but not in the cerebellum. Due to the heterogeneity of outcomes in the UHR population, further longitudinal studies are needed to determine the true difference of Glu of those subjects that will convert to psychosis. Replication of our results and the results of longitudinal studies could help to develop a better prediction algorithm for those subjects that will develop a primary psychotic disorder.

\section{ACKNOWLEDGEMENTS}

This work was supported by Consejo Nacional de Ciencia y Tecnología (CONACyT) research grants 89530 and 119280 to A Graff-Guerrero and $\mathrm{C}$ de la Fuente-Sandoval, respectively, CONACyT Scholarship to $\mathrm{P}$ León-Ortiz, and Sistema Nacional de Investigadores (SNI) to $\mathrm{C}$ de la FuenteSandoval, J Ramírez-Bermúdez, and A Graff-Guerrero. We wish to thank, Drs Jesús Taboada and Katiuzka Cázares for facilities for the development of this study. CONACyT and SNI had no further role in study design; in the collection, analysis and interpretation of data, in the writing of the report, and in the decision to submit the paper for publication.

\section{DISCLOSURE}

Camilo de la Fuente-Sandoval has received grant support from Janssen, professional services compensation from IMS Health, and speaker compensation from Eli Lilly. Rafael Favila is an employee of GE Healthcare. Pablo León-Ortiz, Sylvana Stephano, and Jesús Ramírez-Bermúdez declare no conflict of interest. David Mamo has received grant support and consultant fees from Pfizer, Bristol-Myers Squibb, and AstraZeneca. Ariel Graff-Guerrero has received professional services compensation from Abbott Laboratories, grant support from Janssen, and speaker compensation from Eli Lilly.

\section{REFERENCES}

Aalto S, Hirvonen J, Scheinin H, Någren K, Vilkman H, Hietala J et al (2002). Ketamine does not decrease striatal dopamine D2 receptor binding in man. Psychopharmacology 164: 401.

Aalto S, Ihalainen J, Hirvonen J, Kajander J, Scheinin H, Tanila H et al (2005). Cortical glutamate-dopamine interaction and ketamine-induced psychotic symptoms in man. Psychopharmacology (Berl) 182: 375-383.

Abbott C, Bustillo J (2006). What have we learned from proton magnetic resonance spectroscopy about schizophrenia? A critical update. Curr Opin Psychiatry 19: 135-139.

Abi-Dargham A, Gil R, Krystal J, Baldwin RM, Seibyl JP, Bowers M et al (1998). Increased striatal dopamine transmission in schizophrenia: confirmation in a second cohort. Am J Psychiatry 155: 761-767.

APA (2000). Diagnostic and Statistical Manual of Mental Disorders $D S M-I V-T R$ 4th edn American Psychiatric Association: Washington, DC, USA.

Ariyannur PS, Madhavarao CN, Namboodiri AM (2008). Nacetylaspartate synthesis in the brain: mitochondria vs microsomes. Brain Res 1227: 34-41.

Auer DP, Wilke M, Grabner A, Heidenreich JO, Bronisch T, Wetter TC (2001). Reduced NAA in the thalamus and altered membrane and glial metabolism in schizophrenic patients detected by $1 \mathrm{H}-$ MRS and tissue segmentation. Schizophr Res 52: 87-99.

Barker PB (2001). N-acetyl aspartate-a neuronal marker? Ann Neurol 49: 423-424.

Bartha R, Williamson PC, Drost DJ, Malla A, Carr TJ, Cortese L et al (1997). Measurement of glutamate and glutamine in the medial prefrontal cortex of never-treated schizophrenic patients and healthy controls by proton magnetic resonance spectroscopy. Arch Gen Psychiatry 54: 959-965.

Bates TE, Strangward M, Keelan J, Davey GP, Munro PM, Clark JB (1996). Inhibition of $\mathrm{N}$-acetylaspartate production: implications for 1H MRS studies in vivo. Neuroreport 7: 1397-1400.

Borgwardt SJ, Riecher-Rossler A, Dazzan P, Chitnis X, Aston J, Drewe $M$ et al (2007). Regional gray matter volume abnormalities in the at risk mental state. Biol Psychiatry 61: 1148-1156.

Breier A, Adler CM, Weisenfeld N, Su TP, Elman I, Picken L et al (1998). Effects of NMDA antagonism on striatal dopamine release in healthy subjects: application of a novel PET approach. Synapse 29: 142-147.

Brodal P (2004). The central nervous system: structure and function, 3rd edn Oxford University Press: Oxford, New York.

Bustillo JR, Rowland LM, Jung R, Brooks WM, Qualls C, Hammond $\mathrm{R}$ et al (2008). Proton magnetic resonance spectroscopy during initial treatment with antipsychotic medication in schizophrenia. Neuropsychopharmacology 33: 2456-2466.

Bustillo JR, Rowland LM, Lauriello J, Petropoulos H, Hammond R, Hart B et al (2002). High choline concentrations in the caudate nucleus in antipsychotic-naive patients with schizophrenia. $A m \mathrm{~J}$ Psychiatry 159: 130-133.

Bustillo JR, Rowland LM, Mullins P, Jung R, Chen H, Qualls C et al (2010). 1H-MRS at 4 tesla in minimally treated early schizophrenia. Mol Psychiatry 15: 629-636.

Cadenhead KS (2002). Vulnerability markers in the schizophrenia spectrum: implications for phenomenology, genetics, and the identification of the schizophrenia prodrome. Psychiatr Clin North Am 25: 837-853. 
Cadenhead KS, Addington J, Cannon T, Cornblatt B, McGlashan T, Perkins D et al (2010). Treatment history in the psychosis prodrome: characteristics of the North American Prodrome Longitudinal Study Cohort. Early Interv Psychiatry 4: 220-226.

Camps M, Cortes R, Gueye B, Probst A, Palacios JM (1989). Dopamine receptors in human brain: Autoradiographic distribution of D2 sites. Neuroscience 28: 275.

Cannon TD, Cadenhead K, Cornblatt B, Woods SW, Addington J, Walker E et al (2008). Prediction of psychosis in youth at high clinical risk: a multisite longitudinal study in North America. Arch Gen Psychiatry 65: 28-37.

Carlsson M, Carlsson A (1990). Interactions between glutamatergic and monoaminergic systems within the basal ganglia-implications for schizophrenia and Parkinson's disease. Trends Neurosci 13: $272-276$.

Cepeda C, Levine MS (1998). Dopamine and N-methyl-D-aspartate receptor interactions in the neostriatum. Dev Neurosci 20: 1-18.

Chua SE, Cheung C, Cheung V, Tsang JT, Chen EY, Wong JC et al (2007). Cerebral grey, white matter and csf in never-medicated, first-episode schizophrenia. Schizophr Res 89: 12-21.

Clementi V, Tonon C, Lodi R, Malucelli E, Barbiroli B, Iotti S (2005). Assessment of glutamate and glutamine contribution to in vivo $\mathrm{N}$-acetylaspartate quantification in human brain by (1) $\mathrm{H}-$ magnetic resonance spectroscopy. Magn Reson Med 54: 1333-1339.

David HN, Ansseau M, Abraini JH (2005). Dopamine-glutamate reciprocal modulation of release and motor responses in the rat caudate-putamen and nucleus accumbens of "intact" animals. Brain Res Brain Res Rev 50: 336-360.

De Keyser J, Claeys A, De Backer JP, Ebinger G, Roels F, Vauquelin $\mathrm{G}$ (1988). Autoradiographic localization of D1 and D2 dopamine receptors in the human brain. Neurosci Lett 91: 142-147.

de la Fuente-Sandoval C, Favila R, Alvarado P, Leon-Ortiz P, DiazGalvis L, Amezcua C et al (2009). Glutamate increase in the associative striatum in schizophrenia: a longitudinal magnetic resonance spectroscopy preliminary study. Gac Med Mex 145: 109-113.

Di Costanzo A, Trojsi F, Tosetti M, Giannatempo GM, Nemore F, Piccirillo $\mathrm{M}$ et al (2003). High-field proton MRS of human brain. Eur J Radiol 48: 146-153.

Di Costanzo A, Trojsi F, Tosetti M, Schirmer T, Lechner SM, Popolizio T et al (2007). Proton MR spectroscopy of the brain at 3 T: an update. Eur Radiol 17: 1651-1662.

Dum RP, Strick PL (2003). An unfolded map of the cerebellar dentate nucleus and its projections to the cerebral cortex. $J$ Neurophysiol 89: 634-639.

Edden RA, Pomper MG, Barker PB (2007). In vivo differentiation of $\mathrm{N}$-acetyl aspartyl glutamate from $\mathrm{N}$-acetyl aspartate at 3 Tesla. Magn Reson Med 57: 977-982.

Eluri R, Paul C, Roemer R, Boyko O (1998). Single-voxel proton magnetic resonance spectroscopy of the pons and cerebellum in patients with schizophrenia: a preliminary study. Psychiatry Res 84: 17-26.

Farde L, Wiesel FA, Halldin C, Sedvall G (1988). Central D2dopamine receptor occupancy in schizophrenic patients treated with antipsychotic drugs. Arch Gen Psychiatry 45: 71-76.

First MB, Spitzer RL, Williams JB, Gibbon M (1997). Structured Clinical Interview for DSM-IV Disorders (SCID). American Psychiatric Association: Washington, DC.

Friston KJ, Ashburner J, Frith CD, Poline JB, Heather JD, Frackowiak RSJ (1995). Spatial registration and normalization of images. Hum Brain Mapp 3: 165-189.

Grace AA (1991). Phasic versus tonic dopamine release and the modulation of dopamine system responsivity: a hypothesis for the etiology of schizophrenia. Neuroscience 41: 1-24.

Grace AA (1993). Cortical regulation of subcortical dopamine systems and its possible relevance to schizophrenia. J Neural Transm 91: 111-134.
Grace AA (2000). Gating of information flow within the limbic system and the pathophysiology of schizophrenia. Brain Res Brain Res Rev 31: 330-341.

Graff-Guerrero A, Willeit M, Ginovart N, Mamo D, Mizrahi R, Rusjan $P$ et al (2008). Brain region binding of the $\mathrm{D} 2 / 3$ agonist [11C]-(+)-PHNO and the D2/3 antagonist [11C]raclopride in healthy humans. Hum Brain Mapp 29: 400-410.

Hietala J, Syvalahti E, Vilkman H, Vuorio K, Rakkolainen V, Bergman J et al (1999). Depressive symptoms and presynaptic dopamine function in neuroleptic-naive schizophrenia. Schizophr Res 35: 41-50.

Horrobin DF, Glen AI, Vaddadi K (1994). The membrane hypothesis of schizophrenia. Schizophr Res 13: 195-207.

Howes OD, Kapur S (2009a). The dopamine hypothesis of schizophrenia: version III-the final common pathway. Schizophr Bull 35: 549-562.

Howes OD, Montgomery AJ, Asselin MC, Murray RM, Valli I, Tabraham $\mathrm{P}$ et al (2009b). Elevated striatal dopamine function linked to prodromal signs of schizophrenia. Arch Gen Psychiatry 66: $13-20$.

Hurd R, Sailasuta N, Srinivasan R, Vigneron DB, Pelletier D, Nelson SJ (2004). Measurement of brain glutamate using TEaveraged PRESS at 3T. Magn Reson Med 51: 435-440.

Jahshan C, Heaton RK, Golshan S, Cadenhead KS (2010). Course of neurocognitive deficits in the prodrome and first episode of schizophrenia. Neuropsychology 24: 109-120.

Javitt DC (2007). Glutamate and schizophrenia: phencyclidine, Nmethyl-D-aspartate receptors, and dopamine-glutamate interactions. Int Rev Neurobiol 78: 69-108.

Javitt DC, Zukin SR (1991). Recent advances in the phencyclidine model of schizophrenia. Am J Psychiatry 148: 1301-1308.

Jayakumar PN, Venkatasubramanian G, Gangadhar BN, Janakiramaiah N, Keshavan MS (2005). Optimized voxel-based morphometry of gray matter volume in first-episode, antipsychoticnaive schizophrenia. Prog Neuropsychopharmacol Biol Psychiatry 29: $587-591$.

Kapur S (2003). Psychosis as a state of aberrant salience: a framework linking biology, phenomenology, and pharmacology in schizophrenia. Am J Psychiatry 160: 13-23.

Kapur S, Zipursky R, Jones C, Remington G, Houle S (2000). Relationship between dopamine $\mathrm{D}(2)$ occupancy, clinical response, and side effects: a double-blind PET study of firstepisode schizophrenia. Am J Psychiatry 157: 514-520.

Kegeles LS, Abi-Dargham A, Frankle WG, Gil R, Cooper TB, Slifstein $\mathrm{M}$ et al (2010). Increased synaptic dopamine function in associative regions of the striatum in schizophrenia. Arch Gen Psychiatry 67: 231-239.

Kegeles LS, Abi-Dargham A, Zea-Ponce Y, Rodenhiser-Hill J, Mann JJ, Van Heertum RL et al (2000). Modulation of amphetamineinduced striatal dopamine release by ketamine in humans: implications for schizophrenia. Biol Psychiatry 48: 627-640.

Kegeles LS, Martinez D, Kochan LD, Hwang DR, Huang Y, Mawlawi $\mathrm{O}$ et al (2002). NMDA antagonist effects on striatal dopamine release: Positron emission tomography studies in humans. Synapse 43: 19.

Kelly RM, Strick PL (2003). Cerebellar loops with motor cortex and prefrontal cortex of a nonhuman primate. J Neurosci 23: 8432-8444.

Keshavan MS, Dick RM, Diwadkar VA, Montrose DM, Prasad KM, Stanley JA (2009). Striatal metabolic alterations in non-psychotic adolescent offspring at risk for schizophrenia: a (1)H spectroscopy study. Schizophr Res 115: 88-93.

Kulagina NV, Zigmond MJ, Michael AC (2001). Glutamate regulates the spontaneous and evoked release of dopamine in the rat striatum. Neuroscience 102: 121-128.

Laruelle M, Abi-Dargham A, Van Dyck CH, Gil R, D'Souza CD, Erdos J et al (1996). Single photon emission computerized tomography imaging of amphetamine-induced dopamine 
release in drug-free schizophrenic subjects. Proc Natl Acad Sci USA 93: 9235.

Lehericy S, Ducros M, Krainik A, Francois C, Van de Moortele PF, Ugurbil $\mathrm{K}$ et al (2004). 3-D diffusion tensor axonal tracking shows distinct SMA and pre-SMA projections to the human striatum. Cereb Cortex 14: 1302-1309.

Levine MS, Cepeda C (1998). Dopamine modulation of responses mediated by excitatory amino acids in the neostriatum. $A d v$ Pharmacol 42: 724-729.

Lieberman JA, Stroup TS, McEvoy JP, Swartz MS, Rosenheck RA, Perkins DO et al (2005). Effectiveness of antipsychotic drugs in patients with chronic schizophrenia. $N$ Engl J Med 353: $1209-1223$.

Lutkenhoff ES, van Erp TG, Thomas MA, Therman S, Manninen M, Huttunen MO et al (2010). Proton MRS in twin pairs discordant for schizophrenia. Mol Psychiatry 15: 308-318.

Mamo D, Graff A, Mizrahi R, Shammi CM, Romeyer F, Kapur S (2007). Differential effects of aripiprazole on D(2), 5-HT(2), and 5-HT(1A) receptor occupancy in patients with schizophrenia: a triple tracer PET study. Am J Psychiatry 164: 1411-1417.

Mawlawi O, Martinez D, Slifstein M, Broft A, Chatterjee R, Hwang $\mathrm{DR}$ et al (2001). Imaging human mesolimbic dopamine transmission with positron emission tomography: I. Accuracy and precision of $\mathrm{D}(2)$ receptor parameter measurements in ventral striatum. J Cereb Blood Flow Metab 21: 1034-1057.

Mayer D, Spielman DM (2005). Detection of glutamate in the human brain at $3 \mathrm{~T}$ using optimized constant time point resolved spectroscopy. Magn Reson Med 54: 439-442.

Middleton FA, Strick PL (2001). Cerebellar projections to the prefrontal cortex of the primate. J Neurosci 21: 700-712.

Miller TJ, McGlashan TH, Rosen JL, Cadenhead K, Cannon T, Ventura J et al (2003). Prodromal assessment with the structured interview for prodromal syndromes and the scale of prodromal symptoms: predictive validity, interrater reliability, and training to reliability. Schizophr Bull 29: 703-715.

Moghaddam B, Adams B, Verma A, Daly D (1997). Activation of glutamatergic neurotransmission by ketamine: a novel step in the pathway from NMDA receptor blockade to dopaminergic and cognitive disruptions associated with the prefrontal cortex. J Neurosci 17: 2921-2927.

O’Neill J, Levitt J, Caplan R, Asarnow R, McCracken JT, Toga AW et al (2004). 1H MRSI evidence of metabolic abnormalities in childhood-onset schizophrenia. Neuroimage 21: 1781-1789.

Ohrmann P, Siegmund A, Suslow T, Spitzberg K, Kersting A, Arolt $\mathrm{V}$ et al (2005). Evidence for glutamatergic neuronal dysfunction in the prefrontal cortex in chronic but not in first-episode patients with schizophrenia: a proton magnetic resonance spectroscopy study. Schizophr Res 73: 153-157.

Olbrich HM, Valerius G, Rusch N, Buchert M, Thiel T, Hennig J et al (2008). Frontolimbic glutamate alterations in first episode schizophrenia: evidence from a magnetic resonance spectroscopy study. World J Biol Psychiatry 9: 59-63.

Olney JW, Farber NB (1995). Glutamate receptor dysfunction and schizophrenia. Arch Gen Psychiatry 52: 998-1007.

Olney JW, Labruyere J, Price MT (1989). Pathological changes induced in cerebrocortical neurons by phencyclidine and related drugs. Science 244: 1360-1362.

Pantelis C, Velakoulis D, McGorry PD, Wood SJ, Suckling J, Phillips LJ et al (2003). Neuroanatomical abnormalities before and after onset of psychosis: a cross-sectional and longitudinal MRI comparison. Lancet 361: 281-288.

Provencher SW (1993). Estimation of metabolite concentrations from localized in vivo proton NMR spectra. Magn Reson Med 30: 672-679.

Purdon SE, Valiakalayil A, Hanstock CC, Seres P, Tibbo P (2008). Elevated $3 \mathrm{~T}$ proton MRS glutamate levels associated with poor
Continuous Performance Test (CPT-0X) scores and genetic risk for schizophrenia. Schizophr Res 99: 218-224.

Rajji TK, Ismail Z, Mulsant BH (2009). Age at onset and cognition in schizophrenia: meta-analysis. Br J Psychiatry 195: 286-293.

Rowland LM, Bustillo JR, Mullins PG, Jung RE, Lenroot R, Landgraf E et al (2005). Effects of ketamine on anterior cingulate glutamate metabolism in healthy humans: a 4 -T proton MRS study. Am J Psychiatry 162: 394-396.

Ruhrmann S, Schultze-Lutter F, Salokangas RK, Heinimaa M, Linszen D, Dingemans P et al (2010). Prediction of psychosis in adolescents and young adults at high risk: results from the prospective European prediction of psychosis study. Arch Gen Psychiatry 67: 241-251.

Saraceno B (2002). The WHO World Health Report 2001 on mental health. Epidemiol Psichiatr Soc 11: 83-87.

Sato M, Numachi Y, Hamamura T (1992). Relapse of paranoid psychotic state in methamphetamine model of schizophrenia. Schizophr Bull 18: 115-122.

Schmahmann JD, Pandya DN (1995). Prefrontal cortex projections to the basilar pons in rhesus monkey: implications for the cerebellar contribution to higher function. Neurosci Lett 199: $175-178$.

Seeman P, Kapur S (2000). Schizophrenia: more dopamine, more D2 receptors. Proc Natl Acad Sci USA 97: 7673-7675.

Segovia G, Del Arco A, Mora F (1997). Endogenous glutamate increases extracellular concentrations of dopamine, GABA, and taurine through NMDA and AMPA/kainate receptors in striatum of the freely moving rat: a microdialysis study. J Neurochem 69: 1476-1483.

Sharp FR, Tomitaka M, Bernaudin M, Tomitaka S (2001). Psychosis: pathological activation of limbic thalamocortical circuits by psychomimetics and schizophrenia? Trends Neurosci 24: 330-334.

Smith GS, Schloesser R, Brodie JD, Dewey SL, Logan J, Vitkun SA et al (1998). Glutamate modulation of dopamine measured in vivo with positron emission tomography (PET) and $11 \mathrm{C}$ raclopride in normal human subjects. Neuropsychopharmacology 18: 18-25.

Stanley JA, Kipp H, Greisenegger E, MacMaster FP, Panchalingam $\mathrm{K}$, Pettegrew JW et al (2006). Regionally specific alterations in membrane phospholipids in children with ADHD: An in vivo 31P spectroscopy study. Psychiatry Res 148: 217-221.

Steen RG, Hamer RM, Lieberman JA (2005). Measurement of brain metabolites by $1 \mathrm{H}$ magnetic resonance spectroscopy in patients with schizophrenia: a systematic review and meta-analysis. Neuropsychopharmacology 30: 1949-1962.

Stone JM, Day F, Tsagaraki H, Valli I, McLean MA, Lythgoe DJ et al (2009). Glutamate dysfunction in people with prodromal symptoms of psychosis: relationship to gray matter volume. Biol Psychiatry 66: 533-539.

Stone JM, Howes OD, Egerton A, Kambeitz J, Allen P, Lythgoe DJ et al (2010). Altered relationship between hippocampal glutamate levels and striatal dopamine function in subjects at ultra high risk of psychosis. Biol Psychiatry 68: 599-602.

Théberge J, Al-Semaan Y, Williamson PC, Menon RS, Neufeld RW, Rajakumar $\mathrm{N}$ et al (2003). Glutamate and glutamine in the anterior cingulate and thalamus of medicated patients with chronic schizophrenia and healthy comparison subjects measured with 4.0-T proton MRS. Am J Psychiatry 160: 2231-2233.

Théberge J, Bartha R, Drost DJ, Menon RS, Malla A, Takhar J et al (2002). Glutamate and glutamine measured with $4.0 \mathrm{~T}$ proton MRS in never-treated patients with schizophrenia and healthy volunteers. Am J Psychiatry 159: 1944-1946.

Théberge J, Williamson KE, Aoyama N, Drost DJ, Manchanda R, Malla AK et al (2007). Longitudinal grey-matter and glutamatergic losses in first-episode schizophrenia. Br J Psychiatry 191: 325-334. 
Tibbo P, Hanstock CC, Asghar S, Silverstone P, Allen PS (2000). Proton magnetic resonance spectroscopy (1H-MRS) of the cerebellum in men with schizophrenia. J Psychiatry Neurosci 25: $509-512$.

Tibbo P, Hanstock C, Valiakalayil A, Allen P (2004). 3-T proton MRS investigation of glutamate and glutamine in adolescents at high genetic risk for schizophrenia. Am J Psychiatry 161: 1116-1118.

van Elst LT, Valerius G, Buchert M, Thiel T, Rusch N, Bubl E et al (2005). Increased prefrontal and hippocampal glutamate concentration in schizophrenia: evidence from a magnetic resonance spectroscopy study. Biol Psychiatry 58: 724-730.

Villalta-Gil V, Vilaplana M, Ochoa S, Haro JM, Dolz M, Usall J et al (2006). Neurocognitive performance and negative symptoms: are they equal in explaining disability in schizophrenia outpatients? Schizophr Res 87: 246-253.

Vollenweider FX, Vontobel P, Oye I, Hell D, Leenders KL (2000). Effects of (S)-ketamine on striatal dopamine: a [11C]raclopride
PET study of a model psychosis in humans. J Psychiatr Res 34: $35-43$.

West AR, Floresco SB, Charara A, Rosenkranz JA, Grace AA (2003). Electrophysiological interactions between striatal glutamatergic and dopaminergic systems. Ann N Y Acad Sci 1003: 53-74.

Wood SJ, Kennedy D, Phillips LJ, Seal ML, Yucel M, Nelson B et al (2010). Hippocampal pathology in individuals at ultra-high risk for psychosis: a multi-modal magnetic resonance study. Neuroimage 52: 62-68.

Yung AR, McGorry PD (1996). The prodromal phase of firstepisode psychosis: past and current conceptualizations. Schizophr Bull 22: 353-370.

Yung AR, Phillips LJ, Yuen HP, Francey SM, McFarlane CA, Hallgren $\mathrm{M}$ et al (2003). Psychosis prediction: 12-month follow up of a high-risk ("prodromal") group. Schizophr Res 60: 21-32.

Zhang Y, Marenco S, Shen J (2007). Correction of frequency and phase variations induced by eddy currents in localized spectroscopy with multiple echo times. Magn Reson Med 58: 174-178. 